\title{
Development of dental clinical research in Brazil - a few (new) ethical challenges
}

\section{Dalton Luiz de Paula Ramos}

Head Professor of Bioethics, School of Dentistry, University of São Paulo. Sitting Member of the National Committee of Research Ethics (CONEP/CNS), Ministry of Health.
W e have witnessed a growth in dental clinical research in Brazil over the last three decades, both qualitatively and quantitatively. This claim is supported by the annual meetings of the Brazilian Society of Dental Research. In its 2011 edition, the event has showcased more than 2,000 approved studies - many of which represent clinical research. The growing participation of Brazilian researchers in meetings of the International Association for Dental Research (IADR) also reflects this trend, further confirming the international excellence of the dental research conducted in our country.

As to the ethical issue, many advances have been made. The dental community has adhered to and complied with the parameters of the ethical regulations put forth by CNS Resolution N. 196/96. A noteworthy effort has been made by dental researchers to obtain free and informed consent by research subjects, and greater care has been taken in evaluating the risks and benefits of research projects.

Nevertheless, as is inherent to the dynamics of scientific research, new challenges continue to present themselves. Historically, dental research in Brazil has been conducted in teaching and research institutions, often in the form of activities connected with graduate programs supported by funds from these institutions or from funding agencies, all from the public sector.

This scenario has been changing, and a growing participation by private teaching institutions has been observed, albeit still with a strong contribution from public research funding agencies.

I see a strong trend towards private companies taking a greater stake as collaborators of dental research, along the lines and in the scale of the collaborations already observed in other healthcare areas, such as medical research in the field of pharmaceuticals. Today, what we see is no longer a marginal participation, whereby a firm donates a product to conduct experiments, but rather an expanded model, through multicenter and international research, where the sponsor/company claims an effective participation in the planning of the study and contributes with significant financial support.

This model is now a global trend. In principle, I believe that private enterprise-sponsored scientific research is a positive endeavor, in that it may bring to life large-scale research projects for which public agencies have neither the interest nor the resources required to fund them.

This new reality, however, entails some new ethical challenges.

Questions arise as to the interests in the commercial gains by private firms acting as research sponsors, as a result of the development and/or the 
scientific certification of commercial products. These interests - which are fair per se - should be considered as normal; the ethical question here is that they cannot be the determinant factor of the research. Thus, these interests should be harmonized with the interest of science and those of the researcher, e.g., to abide by the ethical commitment to divulge the research results regardless of the consequences to the image of the product being researched.

The so called "open research", where the sponsor can determine how the results will be used, may be justified by strategic interests concerned with protecting societies and the common good, but this approach becomes unethical when these interests are predominantly unilateral or restricted to a minority.

The interests of sponsors should also be harmonized with those of society in connection with the use of public equipment, particularly when the research entails using research facilities or personnel trained and/or funded by public institutions. This same consideration should be borne in mind when the research involves both public health care institutions and those assisted by them, causing the study to ultimately make use of already limited public healthcare resources.

Additionally, one must consider the issues relating to the transfer of technology. Brazil and the Brazilians should not be viewed as a granary or a herd for the development of research. Brazilian researchers should not be satisfied with just the occasional credit received when the research is published. We should endeavor to establish effective partnerships made through formal contracts, so that the benefits achieved by the experiment may be shared with the Brazilian society.

Most Brazilian researchers conduct their studies according to ethical standards, but they need - and deserve - to receive support so that they may continue to do so.

In this sense, two major fronts should be considered. One refers to a set of actions aiming at strengthening the ethical appreciation system, which in Brazil goes by the name of CEPs/CONEP, which is responsible not only for looking after the interests of research subjects, but also for conceptualizing its own existence and acting as a major partner to researchers, standing by their side so that they don't feel unattended in face of the overpowering interests of institutions.

Another important front is to guarantee the transparency of the whole research development process. To this end, national and public access research registries are being established in our country, such as the Plataforma Brasil and the REBEC - Registro Brasileiro de Ensaios Clínicos, which act together and also with similar international registries (International Clinical Trials Registries Platform - ICTRP). The greater the research conducted behind closed doors, the harder it is to preserve the legitimate interests of science and the common good; conversely, the greater the transparency, the more unreservedly good, ethical and competent researchers can count on the understanding and support of civil society for their honorable work. 